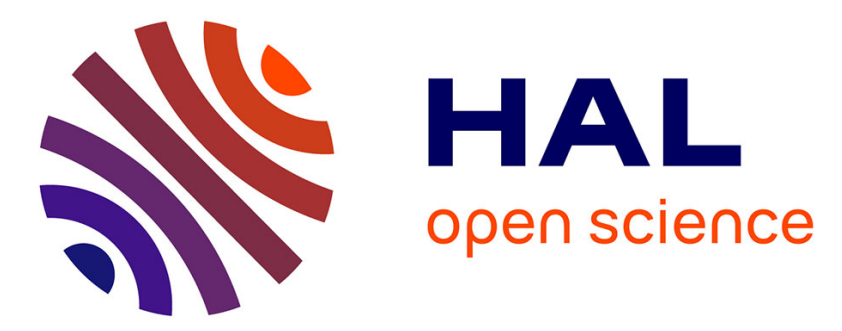

\title{
Positronium inhibition and free volume in chloropolystyrenes studied by positron annihilation
}

A. Baranowski, M. Debowska, K. Jerie, G. Mirkiewicz, J. Rudzinska-Girulska, R. Tadeusz Sikorski

\section{- To cite this version:}

A. Baranowski, M. Debowska, K. Jerie, G. Mirkiewicz, J. Rudzinska-Girulska, et al.. Positronium inhibition and free volume in chloropolystyrenes studied by positron annihilation. Journal de Physique IV Proceedings, 1993, 03 (C4), pp.C4-225-C4-231. 10.1051/jp4:1993434 • jpa-00251477

\section{HAL Id: jpa-00251477 https://hal.science/jpa-00251477}

Submitted on 1 Jan 1993

HAL is a multi-disciplinary open access archive for the deposit and dissemination of scientific research documents, whether they are published or not. The documents may come from teaching and research institutions in France or abroad, or from public or private research centers.
L'archive ouverte pluridisciplinaire HAL, est destinée au dépôt et à la diffusion de documents scientifiques de niveau recherche, publiés ou non, émanant des établissements d'enseignement et de recherche français ou étrangers, des laboratoires publics ou privés. 


\title{
Positronium inhibition and free volume in chloropolystyrenes studied by positron annihilation
}

\author{
A. BARANOWSKI, M. DEBOWSKA, K. JERIE, G. MIRKIEWICZ* , J. RUDZIŃSKA-GIRULSKA \\ and R. TADEUSZ SIKORSKI*
}

Institute of Experimental Physics, Wroctaw University, Maxa Borna 9, 50-204 Wroctaw, Poland * Institute of Organic and Polymer Technology, Technical University of Wroctaw, Wybrezeże Wyspiańskiego 27, 50-370 Wrocław, Poland

\begin{abstract}
Positron annihilation phenomenon has been studied in chloropolystyrenes. PAL and ACAR measurements have been performed in air and at room temperature for amorphous samples of different chlorine content. The increase in the latter is followed by the decrease in both the intensity of the narrow component of ACAR curves and the intensity of the longest-lived component $\left(I_{3}\right)$ in PAL spectra. The latter one, related to the ortho-positronium intensity in polystyrene $I_{3}^{0}$, changes according to the formula: $\mathrm{I}_{3} / \mathrm{I}_{3}^{0}=\left[1+\left(19.93^{*} \mathrm{C}\right)^{0.56}\right]^{-1}$ where $\mathrm{C}$ denotes the number of $\mathrm{Cl}$ atoms per unit of the polymer.

The inductive effect produced by the chlorine in chloropolystyrenes is assumed to be the reason of the inhibition of the positronium formation in them. In general the chlorine reactivity towards positrons seems to depend on its position in the polymer structure.

The numerical Laplace inversion technique $/ 1 /$ has been applied to PAL data to recover the radius distribution of free volumes for each sample of the second series. A tendency towards decrease in mean radius of free volumes is seen when chlorine content increases in studied samples. The only exception is the sample in which the highest amount of chlorine atoms has been substituted at $\alpha$-carbons in the aliphatic chain.
\end{abstract}

\section{Introduction}

The positron annihilation phenomenon has been studied in polystyrene from the very beginning of the development of positron annihilation spectroscopy (PAS) /2,3,4,5/up to nowadays /6,7/. Positronium (Ps) formation has been confirmed in this polymer by the existence of the long-lived component in positron lifetime spectra ( $\tau \simeq 2 n s$ ) and its magnetic quenching $/ 8 /$ as well as by the appearance of the narrow component in ACAR curves $/ 5 /$ and the abundance of the three-quantum annihilation events $/ 9 /$. It is supposed that the formation of positronium in polystyrene takes place mainly in the 
benzene rings /10/. The relaxation parameter (i.e. the electron density at the position of the positron forming Ps in polystyrene related to that of free Ps) was estimated in $/ 8 /$ as equal to $0.80 \mp 0.06$ indicating the relaxation of the Ps. It has been established $/ 11 /$ that:

1/ introduction of chlorine into polystyrene changes thermal stability of samples according to the position of chlorine atoms in polymer structure

2/ the highest thermal stability has been observed for samples with chlorine substituted to benzene rings

$3 /$ in chloropolystyrene with chlorine atoms introduced into the aliphatic parts of its structure the dehydrochlorination takes place easily

4/ the chlorine atoms added to benzene rings are more easily detachable than the ones being in aliphatic chain.

\section{Experimental}

Samples. Polystyrene and chloropolystyrenes

Two series of samples were studied. The first one included polystyrene (PSP-the raw material and PSB) and one chloropolystyrene (PO7), while the second-the commercial polystyrene (AOP-the raw material) and five chloropolystyrene samples (AOW, AO3, AO4, AO6, AO48). Further characteristics of samples as chlorine content and its distribution are given in Table $\mathrm{I}$. All the studied samples were amorphous as it was proved by X-ray diffraction studies. Powders of each sample, except PSB which was in bulk form, were formed into discs, of diameter equal to $20 \mathrm{~mm}$ and of thickness equal to $3 \mathrm{~mm}$, under the pressure of 3 tons.

Polymer preparation and characterization

Table I. Chlorine content in studied samples.

\begin{tabular}{|c|c|c|c|c|c|}
\hline \multirow{4}{*}{\multicolumn{2}{|c|}{ SAMILE }} & \multicolumn{4}{|c|}{ CHLORINE CONTENT } \\
\hline & & \multirow{3}{*}{ [wt. \%] } & \multicolumn{3}{|c|}{ [Cl atom/unit] } \\
\hline & & & \multirow{2}{*}{$\begin{array}{l}\text { uliphattic } \\
\text { chatit }\end{array}$} & \multicolumn{2}{|c|}{ ring } \\
\hline & & & & aromatic & aliphatic \\
\hline Ist series & $\begin{array}{l}\text { PSP } \\
\text { PSB } \\
\text { P'O7 }\end{array}$ & $\begin{array}{c}* \\
36.1\end{array}$ & $\begin{array}{c}- \\
\\
1.3\end{array}$ & : & $\begin{array}{c}\dot{-} \\
0.3\end{array}$ \\
\hline 2nd series & $\begin{array}{l}\text { AOP } \\
\text { AOW } \\
\text { AO3 } \\
\text { AO4 } \\
\text { AO6 } \\
\text { AO48 }\end{array}$ & $\begin{array}{l}. \\
1.1 \\
3.6 \\
15.3 \\
30.8 \\
66.0\end{array}$ & $\begin{array}{c}y \text { values } \\
- \\
0.013 \\
0.1 \\
0.5 \\
1.3 \\
0.6\end{array}$ & $\begin{array}{c}- \\
- \\
- \\
- \\
4.9\end{array}$ & i. \\
\hline
\end{tabular}

The polystyrene samples (PSP and PSB) were obtained by the radical polymerization of styrene in benzene solutions, the procedure desctibed in $/ 12 /$. The chlorination of polystyrene was carried out with sulphuryl chloride in two ways: a) radical-initiation (samples PO7, AOW, AO3, AO4, AO6) $/ 13 /$ and b) ionic catalysis (sample AO48) /14/. The chlorine content was determined using the Schöniger method /15/.

The positions of the chlorine atoms in the chlorinated polystyrenes depend on the mechanism of chlorination. In the chloropolystyrenes obtained in radical-initiated reactions, the chlorine atoms were substituted on the aliphatic part of the polymer (samples AOW, A03, AO4, AO6) and as in case of the sample $\mathrm{PO} 7$ added to the cyclic aliphatic ring and substituted on the chain. 
The general formula of samples AOW-AOG is<smiles>CCCc1ccccc1</smiles>

with values of $y$ given in Table I while the formula of the sample PO7 is<smiles>CI(Cl)Cc1ccccc1</smiles>

$95 \%$

$5 \%$

In the chloropolystyrene A048, obtained by the ionic chlorination of polystyrene, the chlorine atoms were substituted on the aromatic rings of the polystyrene and on the aliphatic chain. The formula of the sample $A 048$ is

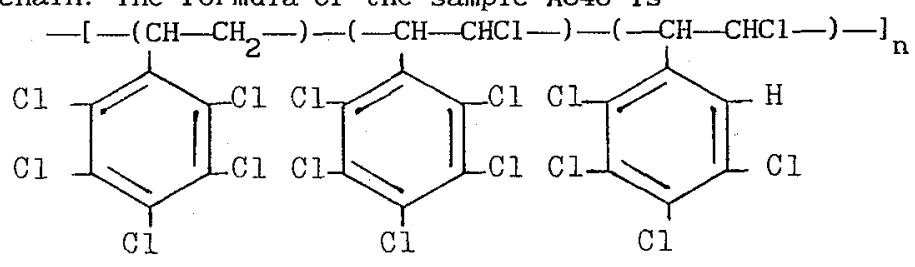

All structures of the chloropolystyrenes were established with use of the $1_{H-N M R}$, IR

All structures of the chloropolystyrenes were established with use of the $1_{H-N M R}$, IR

All structures of the chloropolystyrenes were established with use of the $1_{H-N M R}$, IR spectroscopy techniques and elementary analysis $/ 13 /$.

Measurements

ACAR and PAL techniques were used in our studies of polystyrene and chloropolystyrene samples. The two kinds of measurements were performed in air at $R$. T.

ACAR measurements

ACAR measurements were performed from -29 to +29 mrad with use of the LS spectrometer of angular resolution with FWHM equal to 0.8 mrad, described in details in $/ 16 \%$. Data were accumulated with the step of 0.5 mrad for the period of $2 * 10^{3} \mathrm{~s}$ at each point resulting in about $8^{*} 10^{4}$ counts at the peak of each distribution with background intensity reaching $3 \%$ of the peak value. The positrons were produced upon desintegration of ${ }^{22} \mathrm{Na}$ nuclei in the source of $15 \mathrm{mCi}$ activity.

PAL measurements

A conventional fast-slow coincidence system with plastic, cylindrical scintillators $\mathrm{NE} 111$ (20mm*20mm) was used for measuring the lifetime spectra. The positron source, ${ }^{22} \mathrm{Na}$ of activity $15 \mu \mathrm{Ci}$ was deposited between two identical thin Hostaphan foils (0.8 $\mathrm{mg}^{*} \mathrm{~cm}^{-2}$ each) and then sandwiched between the samples under investigation. A typical decay curve contained about $1 * 10^{6}$ counts and had the peak to background ratio of 2500 . 


\section{Results}

Table II, Results of ACAR measurements.

\begin{tabular}{|c|c|c|c|c|c|c|c|c|c|}
\hline \multirow{2}{*}{$\begin{array}{l}\text { SAMI } \\
\text { P'LE }\end{array}$} & \multicolumn{4}{|c|}{ [FWHM [mrad] } & \multicolumn{4}{|c|}{ IN'IENSI'IIES [\%] } & \multirow{2}{*}{$\begin{array}{l}\text { varinnce } \\
\text { of the fit }\end{array}$} \\
\hline & $G_{\mathrm{l}}$ & $G_{2}$ & $G_{3}$ & F & $\mathrm{l}\left(G_{1}\right)$ & $\mathrm{I}\left(G_{2}\right)$ & $\mathrm{I}\left(G_{3}\right)$ & $\mathrm{I}(\mathrm{F})$ & \\
\hline $\begin{array}{l}\text { PSP } \\
\text { PSI } \\
\text { PO7 }\end{array}$ & $\begin{array}{c}3.0(1.1) \\
3.0(0.1) \\
\cdot\end{array}$ & $\begin{array}{c}8.8(0.1) \\
8.7(0.1) \\
.\end{array}$ & $\begin{array}{l}18.5(2.1) \\
17.7(1.4) \\
17.2(1.5)\end{array}$ & $\begin{array}{c}\dot{\vdots} \\
9.4(0.1)\end{array}$ & $\begin{array}{c}6.9(1,1) \\
6.9(11.1) \\
.\end{array}$ & $\begin{array}{c}88.5(0.3) \\
88.3(0.3) \\
-\end{array}$ & $\begin{array}{l}4.6(0.3) \\
4.8(0.3) \\
0.0(0.3)\end{array}$ & $\frac{\cdot}{94.0(0.3)}$ & $\begin{array}{l}1.41 \\
1.19 \\
1.34\end{array}$ \\
\hline $\begin{array}{l}\text { AOP } \\
\text { AOW } \\
\wedge O 3 \\
\wedge O 4 \\
A O 6 \\
\wedge O 48\end{array}$ & $\begin{array}{c}3.1(0.2) \\
2.8(0.2) \\
2.5(0.3) \\
\vdots \\
\vdots\end{array}$ & $\begin{array}{c}8.6(0.1) \\
8.8(0.1) \\
8.8(0.1) \\
\vdots \\
-\end{array}$ & $\begin{array}{l}15.6(1.7) \\
17.9(2.1) \\
21.8(3.6) \\
15.3(1.1) \\
18.0(1.6) \\
16.8(1.1)\end{array}$ & $\begin{array}{c}- \\
- \\
8.7(1.2) \\
9.2(0.1) \\
9.3(0.1)\end{array}$ & $\begin{array}{c}8.9(0.2) \\
3.9(0.1) \\
2.3(0.1) \\
\vdots \\
\vdots\end{array}$ & $\begin{array}{c}85.4(0.3) \\
92.0(0.3) \\
94.6(1) .3) \\
- \\
-\end{array}$ & $\begin{array}{l}5.7(0.3) \\
4.1(0.3) \\
3.2(0.3) \\
9.2(1.3) \\
5.0(0.2) \\
7.7(0.3)\end{array}$ & $\begin{array}{c}: \\
: \\
91,8(0,3) \\
95,0(0,2) \\
92.3(0.3)\end{array}$ & $\begin{array}{l}1.18 \\
1.67 \\
1.53 \\
1.62 \\
1.29 \\
1.51\end{array}$ \\
\hline
\end{tabular}

The ACAR curves were fitted with a sum of gaussians (for samples PSP, PSB, AOP, AOW and AO3) or the sum of the one very broad gaussian and a Ferrell function /17/ (samples PO7, AO48, AO4 and AO6) simultaneously together with a background represented as a sloped straight line, using the computer program FER /18/.

The results of the analysis, i.e. the FWHM and the intensity of each component are given in Table II.

Table III. Results of PAL measurements.

The PAL spectra corrected for positron annihilation in the source (3\%) were fitted with a sum of three exponentials convoluted with the resolution function of the lifetime spectrometer (a sum of two gaussians) plus a constant background, using the program POSITRONFIT /19/. The results of the analysis $i, e$. the 1 ifetimes and the intensities are given in Table III. The analysis of the PAL spectra with use of a method employing numerical Laplace inversion technique /20/ was performed for the samples of the second series. Further details concerning the method are given in $/ 21 / \mathrm{A}$ modified version of Provencher program CONTIN was used to obtain the radius (R) and volume (V) distributions of free-volume cavities. A reference spectrum of $6 \mathrm{~N}$ polycrystaline $\mathrm{Ni}$ was used $\left(\tau_{\mathrm{Ni}}=110 \mathrm{ps}, \mathrm{I}_{\mathrm{N}}=96 \%\right)$. The radius distributions are given

in Fig. 1 .

\section{Discussion}

Comparison of the results for PSP and PSB samples indicates that there is no essential difference in positron annihilation characteristics for powder and bulk polystyrene. The lifetimes for raw samples in both series (PSP and AOP) are very close to those known from literature $/ 6 /$ and being the results of the high precision measurements.

Assuming that in polystyrene the longest-lived component in the lifetime spectra $\left(\tau_{3}, I_{3}\right)$ comes from the ortho-positronium atoms decaying via the pickoff process one can conclude that the positronium formation in chloropolystyrenes is strongly inhibited. The inhibition reveals even at the low content of $\mathrm{Cl}$ atoms (the large decrease in $I_{3}$ follows the little increase in the chlorine content). 


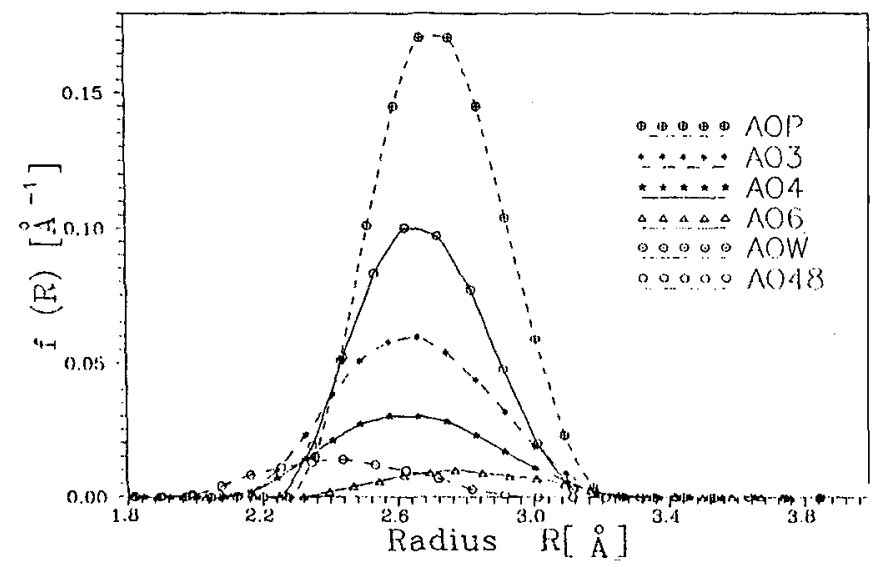

Fig. 1. Free-volume radius distribution functions, $f(R)$. Smooth lines were drawn through the data points for eye-guide purposes only.

In Fig. 2 the decrease in $I_{3}$ is given vs.

Cl content for samples of both series. Using the values of $\Delta \mathrm{I}_{3} / \mathrm{I}_{3}{ }_{3}$ obtained for the sample AO6 of the second series as reflecting the inhibition possibility of $\mathrm{Cl}$ atoms in the aliphatic chain, one can count the additional relative decrease in $I_{3}$ wich takes place in the sample PO7 and is caused by the chlorine atoms attached to the cyclic aliphatic rings. The value of $\Delta \mathrm{I}_{3} / \mathrm{I}_{3}^{\mathrm{O}}$ equal about $12 \%$ per one $\mathrm{Cl}$ atom situated as mentioned above in the polymer structure in PO7 is obtained. The similar comparison between samples $\mathrm{A04}$ and $\mathrm{A048}$ shows that the chlorine atoms substituted in the aromatic rings of the sample A048 don' $t$ give any contribution to the inhibition of the positronium. It seems that the $\mathrm{Cl}$ atoms attached to aliphatic carbons are the active ones in the inhibition of Ps formation.

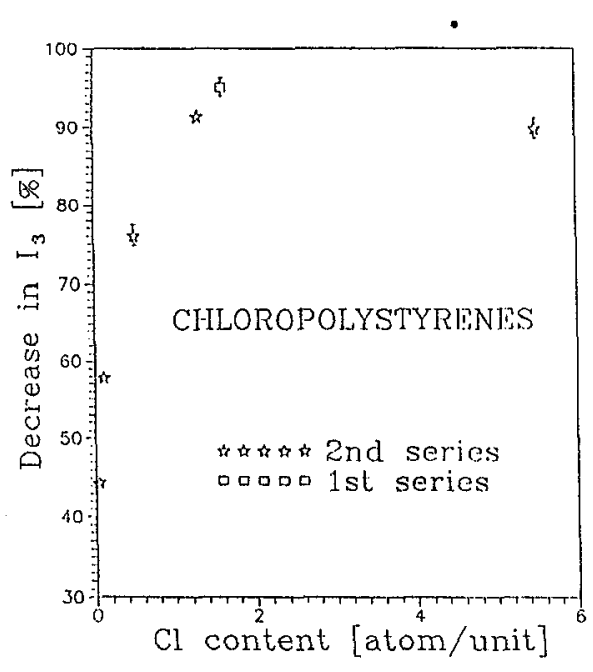

Fig. 2. The decrease in $\mathrm{I}_{3}$ vs. $\mathrm{Cl}$ content.

The general conclusion is that the chlorine inhibits the positronium formation but its reactivity towards positrons depends on its position in the polymer structure, it means on the kind of bond between the halogen and carbon.

The intensities $I_{3}$ vs.chlorine content (C) for the samples of the second series are well fitted with the equation: $I_{3}=I_{3}^{0}\left[1+\left(\alpha{ }^{*} C\right)^{\beta}\right]^{-1}$ where $I_{3}^{0}$ denotes the o-Ps yield in the polystyrene sample (AOP), while $\alpha$ and $\beta$ are the fitting parameters equal respectively to 19.93 [atom/unit $]^{-1}$ and 0.56 (Fig. 3 ).

The above equation has been proposed to represent the o-Ps yield versus the concentration of electron scavengers in solutions /22/. It is based on the assumption that the relative yield of $P s$ is proportional to the relative fraction of geminate electrons which remained unscavenged by the introduced electron scavenger.

According to the spur model the Ps yield in polymers should be large due to the small size of the spur in solids at all, and the high values of dielectric constants in polymers. Relative high contributions of the spur mechanism in the Ps formation were estimated in /23/ for some polymers. 
Fig. 3. $\quad \mathrm{I}_{3} / \mathrm{I}_{3}^{0}$ vs. $\mathrm{Cl}$ content. The experimental data were fitted
with the formula: $I_{3}=I_{3}^{0}\left[1+\left(\alpha^{*} C\right)^{\beta}\right]^{-1}$ using the method of least squares. The fitting parameters $\alpha \& \beta$ are given above.

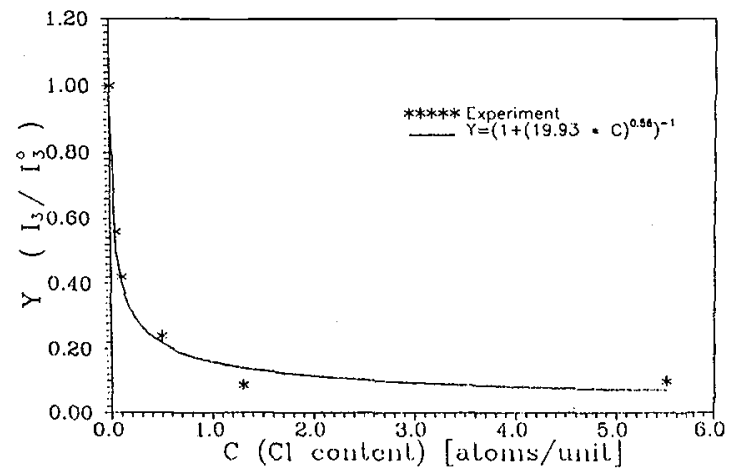

The inhibition of positronium in the frame of the spur model of Ps formation is frequently explained by the possibility of the $\left[\mathrm{Cl}^{-}, \mathrm{e}^{+}\right]$bound state formation. The existence of such state has been proposed many times in case of samples containing $\mathrm{Cl}$ and studied with use of PAS,e. g. in aqueous solutions of $\mathrm{Cl}^{-}$ions $/ 24 /$, in chiorine substituted hydrocarbons in non-polar liquids $/ 25 /$, in polyvinyl chloride on thermal degradation /26/, in fluorinated elastomers with $\mathrm{Cl}$ in side groups /27/ and for alkali chlorides $/ 28 /$.

In $/ 28 /$ the stability of the $\left[\mathrm{Cl}^{-}, e^{+}\right]$bound state was established and its main characteristics were given, e. $g$. the full width at half maximum of the ACAR curve (11.2 mrad) as well as the positron lifetime (328 ps). Thus if the complex [Cl', $\left.\mathrm{e}^{+}\right]$ is formed it doesn't contribute to the long lifetime in the PAL spectra and to the narrow component in the ACAR curves. The changes in positron annihilation characteristics observed by us versus chlorine content don't contradict the supposition that the formation of the $\left[\mathrm{Cl}^{-}, \mathrm{e}^{+}\right]$bound state is the reason of the Ps inhibition in the chloropolystyrenes. There is however a problem in what process the $\mathrm{Cl}^{-}$ions could be produced. The increase in electron charge in vicinity of chlorine atoms is possible as a result of the inductive effect following the introduction of chlorine both into aromatic and aliphatic parts of the chloropolystyrene structure. It is known that introduction of chlorine enlarges the dipole moment of molecules (cf the values of the electric dipole moment in case of bezene and chlorobenzene, 1,2-dichlorobenzene, 1,3-dichlorobenzene, 1,4-dichlorobenzene, toluene and 2-chlorotoluene, 3-chlorotoluene, 4-chlorotoluene, benzyl chloride and 2-chlorobenzyl chioride, 3-chlorobenzyl chloride, 4-chlorobenzyl chloride). Polar molecules with electric dipole moment greater than $1.625 \mathrm{D}$ are guaranteed to possess positron complexes which, within the Bohr-Oppenheimer approximation, are stable with respect to positron detachment /29/. It seems to us that in chloropolystyrenes one may take into account the possibility of existence of the positron-unit complex [RCl, $e^{+}$], possible to view as $\left[\mathrm{Cl}^{-}, e^{+}\right]$complex in the field of an $\mathrm{R}^{+}$ion. The influence of the electric dipole moment of fluorinated benzenes in cyclohexane-dichloromethane and in cyclohexane-carbon tetrachloride mixtures on positronium formation was reported in 130/. From the fig. 1 a tendency towards decrease in mean radius of free volume is seen when chlorine content increases in studies samples. The only exception is the sample AOG in which the highest amount of $\mathrm{Cl}$ atoms was substituted at $\alpha$-carbons in the backbone /13/ That might result in effective stretching and stiffening of the chain.

\section{Acknowledgement}

We are grateful to Dr.R.B. Gregory for making a copy of CONTIN available. 


\section{References}

1/ Gregory, R. B, Procyk, A, in: Positron Annihilation Studies of Fluids, Ed. Sharma, S.C, World Scientific, Singapore 1988, p. 254.

/2/ De Benedetti,S, Richings, H. J, Phys. Rev. 85 (1952) 377

/3/ Bel1,R.E, Graham, R. L, Phys. Rev. 87 (1952) 236

/4/ Bell,R.E, Graham,R. L, Phys.Rev. B 90 (1953) 644

/5/ Page L. A, Heinberg, M, Phys. Rev. 102 (1956) 1545

/6/ Kluin, J.E, Faupel,F, Materials Science Forum, 105-110 (1992) 1613

/7/ Welander, M, Mauer,F.H.J, ibid., p. 1811.

/8/ Bertolaccini,M, Bisi,A, Gambarini,G, Zappa, L, J. Phys.C: Solid State Phys.7 (1974) 3827

19/ Bertolaccini, M, Bussolati, C, Zappa, L, Phys. Rev. 139A (1965) 696

/10/ Thosar, B. V, Kulkarni, V.G, Lagu, R. G, Chandra, G, Phys. Lett. 21 (1966) 647

/11/Sikorski, R. T, Mirkiewicz, G, Varga,J, Biro, O, J. Thermal Anal., 36 (1990) 1795

112/ Łosiew, I, Fedotowa, O, Praktikum Po Chimii Wysokomolekularnych Sojedinienii, Gozchimizdat, Mogkwa (1962).

13/ Mirkiewicz,G, Ph.D. Thesis, to be published.

114/ Sikorski, R. T, Mirkiewicz, G, Eur. Polym. J. 24 (1988) 157

/15/ Pielichowski,J, Puszyński,A, Preparatyka Zwiazkow Wielkoczasteczkowych, Pol itechnika Krakowska, Kraków 1978 p. 142.

/16/ Rozenfeld, B, Baranowski, A, Jerie,K, Nukleonika 19 (1974) 817

/17/ Baranowski, A, Dębowska, E, Appl. Phys. A51 (1990) 23

18. Baranowski, A, Program FER, in a software of the Computer Library of the Department of Applied Nuclear Physics at Wrocław University.

19/ Kirkegaard, P, Pedersen, N. J, Eldrup, M, PATFIT-88: A Data Processing System for Positron Annihilation Spectra on Mainframe and Personal Computers, National Laboratory, 1989.

/20/ Gregory, R. B, Zhu, Y, Nuc1. Instr. \& Methods in Physics Res. A290 (1990) 172

121/ Baranowski, A, Dębowska, M, Jerie, K, Mirkiewicz, G, Rudzińska-Girulska, J, Sikorski,R.T, Acta Phys. Polon., 83 (1993) 239.

122/ references /32/ \& /33/ in Wikander, G, Mogensen, O. E, Pedersen, N. J, Chem. Phys. 77 (1983) 159

/23/ Bisi, A, Gambarini,G, Zappa, L, N.Cim. 2D (1983) 1465

/24/ Mogensen, O.E, Chem. Phys. 37 (1979) 139

125/ Wikander, G, Mogensen, O.E, Pedersen, J, Chem. Phys. 87 (1984) 149

/26/ Khan, M. N.G.A, J. Phys. D3 (1970) 663

127/ Arifov, P. U, Vasserman, S. N, Tishin, S. A, in: Positron Annihilation, Eds. P.C. Jain, R.M. Singru and K.P. Gopinathan, World Scientific, p. 787.

128/ Nuramagambetov, S. B, ibid., p. 770.

/29/ Kurtz,H. A, Jordan, K. D, J. Chem. Phys. 75 (1981) 1876

/30/Zhang, Z, Ito, Y, Tabata, Y, Radiat. Phys. Chem. 36 (1990) 285 